\title{
Práticas Integrativas e Complementares em saúde na formação em Educação Física: avanços, desafios, velhos e novos embates
}

\section{Complementary and integrative medicine in the higher education of physical education: advances, challenges, old and new debates}

\author{
Viviana Graziela de Almeida Vasconcelos Barboni ${ }^{\mathrm{a}}$ \\ (iD) https://orcid.org/0000-0001-7636-217X \\ E-mail: barboniळusp.br \\ Yara Maria de Carvalhob \\ (D) https://orcid.org/0000-0001-8926-355X \\ Email: yaramcœusp.br
}

aUniversidade de São Paulo. Escola de Educação Física $e$ Esportes. São Paulo, SP, Brasil.

bUniversidade de São Paulo. Escola de Educação Física e Esportes. Departamento de Pedagogia do Movimento do Corpo Humano. São Paulo, SP, Brasil.

\section{Correspondência}

Viviana Graziela de Almeida Vasconcelos Barboni

Rua Castro Alves, 217, Centro. Feira de Santana, BA, Brasil. CEP 44003-20I.

\section{Resumo}

A entrada das Práticas Integrativas e Complementares (PICS) nos currículos da área de saúde tem se dado de maneira insatisfatória, e na Educação Física não é diferente. Esse estudo se propõe a analisar a presença dessa temática atualmente na formação superior em Educação Física das universidades públicas federais e estaduais brasileiras, na perspectiva de elucidar quais os desafios, lacunas e avanços que a área enfrenta. Para isso, foi realizada a análise de 172 grades curriculares de graduações na área, os programas de 52 disciplinas em PICS encontradas e as linhas de pesquisa em Programas de PósGraduação e Grupos de Pesquisa liderados por profissionais da área. Os resultados evidenciam pouca inserção do tema nos currículos de graduação e, quando presente, se dão através de ofertas majoritariamente optativas, tecnicista e sem diálogos com o Sistema Único de Saúde. Ainda foi encontrada uma pouca participação da área na produção científica e pós-graduação em PICS.

Palavras-chave: Currículo; Terapias Complementares; SUS. 


\section{Introdução}

The introduction of Complementary and Alternative Medicine (CAM) into undergraduate health programs has been unsatisfactory and this is not different in Physical Education. This study proposes an analysis of the presence of this theme in higher education in Physical Education at Brazilian federal and state public universities, aiming to elucidating the challenges, gaps and advances that the area faces. Thus, an analysis of 172 curriculum grades for undergraduate courses in the area was conducted. The programs of 52 disciplines in CAM and the research lines of Postgraduate Programs and Research Groups led by professionals in the area were also analyzed. The results show little insertion of the theme in the graduation curricula, and when present, they occur in elective and technical subjects, without dialogues with the Brazilian Unified Health System (SUS). There was still a small participation of the area in scientific production and postgraduation in CAM.

Keywords: Curricula; Complementary Therapies; Brazilian National Health System (SUS).
A crescente popularização e o uso de novas práticas terapêuticas em serviços de saúde é uma realidade. Estas práticas, chamadas alternativas, complementares, integrativas, holísticas ou, simplesmente, Práticas Integrativas e Complementares em Saúde (PICS), foram ganhando progressivo espaço no Brasil especialmente após 2006, com a publicação da Política Nacional de Práticas Integrativas e Complementares (PNPIC) pelo Ministério da Saúde (Brasil, 2006).

Com a criação da PNPIC, algumas discussões importantes passam a ser feitas a respeito da consolidação dessa política, dentre elas a da formação profissional para atuação com as práticas. Uma das diretrizes da política prevê o desenvolvimento de estratégias de qualificação para profissionais do SUS que atuam com as PICS e o incentivo à pesquisa científica e inserção de disciplinas nos cursos de graduação e pós-graduação (Brasil, 2006).

Essa entrada nos cursos de graduação, no entanto, tem se dado de maneira lenta e heterogênea. Além disso, o número de cursos de saúde que tem em seu currículo formal o ensino delas é reduzido e, quando ofertadas, são optativas. Como resultado, a maior parte do conhecimento de profissionais de Saúde com Ensino Superior sobre o tema é advindo de leituras pessoais, experiências familiares ou mesmo das mídias e internet, evidenciando a fragilidade da educação formal sobre essas práticas (Gontijo; Nunes, 2017; Couto et al., 2018; Correa; Soares; Muccillo-Baisch, 2018; Salles; Homo; Silva, 2014; Santos et al., 2019).

Para as PICS, que se fundamentam em um referencial vitalista-holístico, essa disputa de espaço nos currículos se dá com disciplinas do referencial biomédico e remonta a perspectiva de mudança de paradigmas no campo de saúde e de reforma do modelo assistencial. No entanto essas divergências paradigmáticas acabam sendo tratadas, muitas vezes, de maneira simplista, excludente e verticalizada, enfraquecendo a proposta de simultaneidade e complementariedade na formação, essencial para o desenvolvimento de um olhar integrativo sobre o processo saúde-doença-cuidado e sobre os sujeitos (Teixeira, 2007; Salles; Homo; Silva, 2014; Nogueira; Nascimento, 2018). 
Assim como em outros cursos de formação superior em saúde, na Educação Física não é diferente. Além de um olhar prioritariamente biologicista focado no processo saúde-doença não oferece o preparo adequado para atuação no SUS, assim como restringe espaço curricular para outras concepções de corpo, movimento e homem, suscitando questionamentos acerca das competências e habilidades que os profissionais da área necessitam desenvolver para a atuação na Saúde Pública (Fraga; Carvalho; Gomes, 2012).

As discussões sobre a abordagem do conteúdo PICS nos currículos de Educação Física ainda é bastante incipiente e tem se movido no sentido de enfocar discussões sobre corpo e corporeidade, e de que forma essa discussão se amplia de um modelo fisiológico e esportivo para outras possibilidades que dialoguem com o referencial vitalista-holístico das PICS e em sintonia com os princípios do SUS. Esse outro olhar sobre o corpo, os sentidos e o movimento consideram a indissociabilidade corpo-mente e levam em consideração, além do biológico, dimensões mais subjetivas do indivíduo como a espiritualidade e a dimensão sensível que habitam o corpo (Gomes; Almeida; Galak, 2019).

Pensando na realidade dos cursos de Educação Física brasileiros que possuem currículos marcados, de modo geral, por carências formativas para atuação no SUS, entende-se que a formação para atuação com PICS torna-se mais um problema a ser sanado nas discussões sobre reformas curriculares.

Assim sendo, esse estudo se propõe a investigar como está se dando a formação em PICS no Ensino Superior de Educação Física em universidades públicas brasileiras na perspectiva de elucidar quais os desafios, lacunas e avanços que a área enfrenta e assim poder fornecer maior embasamento para discussões futuras.

\section{Método}

Este estudo avalia a formação superior em PICS nos cursos de educação física do brasil, em universidades públicas federais e estaduais. foram consideradas PICS, além das 29 práticas reconhecidas pelo ministério da saúde (acupuntura, homeopatia, plantas medicinais e fitoterapia, medicina antroposófica, termalismo social/crenoterapia, arteterapia, medicina ayurvedica, yoga, biodança, meditação, reiki, shantala, osteopatia, quiropraxia, reflexoterapia, musicoterapia, naturopatia, dança circular, terapia comunitária integrativa, apiterapia, aromaterapia, bioenergética, constelação familiar, cromoterapia, geoterapia, hipnoterapia, imposição de mãos, ozonioterapia e terapia de florais), também as medicinas tradicionais, racionalidades médicas e demais práticas encontradas que se orientam pelo referencial vitalista, mesmo não estando incluídas na PNPIC.

A formação superior é entendida nesse trabalho como um projeto político pedagógico que engloba diferentes cenários formativos, seja com foco no ensino, na extensão ou na pesquisa, considerando a inseparabilidade entre essas dimensões nas universidades públicas brasileiras. Por esse motivo, incluímos nas análises um olhar sobre os Programas de Pós-Graduação e Grupos de Pesquisa, para além dos currículos de graduação, compreendendo que a formação no Ensino Superior inclui também essas outras possibilidades.

Para esta análise, foram levantadas as grades curriculares da graduação na área, as ementas e programas das disciplinas de PICS e correlatas ofertadas. Também foram analisados os Programas de Pós-Graduação (PPG) e grupos de pesquisa com linhas de pesquisa em PICS nestas Universidades. O levantamento inicial dos currículos levou em conta cursos cadastrados como Educação Física ativos no país, a partir da lista de cursos superiores de graduação e sequenciais expedida em abril de 2020, disponível no Repositório de Arquivos do MEC (RAMEC) (Brasil, 2020). A partir desse levantamento, foram identificados cursos por região e elementos como tipo de formação (licenciatura ou bacharelado), modalidade (presencial ou a distância) e administração da instituição (pública ou privada).

Para a análise da grade curricular, foram utilizadas as informações disponíveis nos sites oficiais de cada Instituição de Ensino Superior (IES) de matrizes curriculares e Projetos Políticos Pedagógicos (PPP). Os critérios de inclusão foram: pertencer a cursos de graduação em Educação ativos, pertencer a uma IES pública brasileira e com gratuidade integral. Os critérios de exclusão foram: não disponibilizar o acesso à matriz curricular ou ao PPP em portais eletrônicos oficiais do curso. 
Na análise das matrizes curriculares, buscaramse disciplinas de PICS, sendo estas analisadas segundo as categorias: nome da disciplina, carga horária, conteúdo da ementa (ligação com PICS, diálogo com o SUS) e habilidades e competências (se privilegia a formação técnica ou a visão integrativa da saúde, se prevê o desenvolvimento de habilidades e competências para atuação com a prática ou é apenas vivencial).

Para análise dos PPG, avaliou-se apenas a presença ou ausência de linhas de pesquisa que contemplasse PICS, racionalidades em saúde ou medicinas tradicionais. Essa avaliação se deu através de informações disponíveis nos sites oficiais de cada IES, porém foram avaliadas apenas as instituições incluídas na etapa anterior.

Para os Grupos de Pesquisa (GP), utilizouse o banco de dados disponibilizado pela Rede Observa PICS, vinculada à Fiocruz, referente ao mapeamento dos grupos de pesquisa atuantes com PICS no Brasil até 2019 (Sousa; Silva; Ferreira, 2020). Em complementação, foi realizada uma busca parametrizada pelas linhas de pesquisa na base corrente do Diretório dos Grupos de Pesquisa no Brasil do CNPq, em junho de 2020, e feito o cruzamento entre os dois bancos de dados, excluindo as duplicatas. Avaliou-se a presença de lideranças de professores de Educação Física nesses grupos, bem como a predominância de PICS como objeto de estudo.

\section{Resultados e discussão}

Foram analisados para esse estudo 172 matrizes curriculares de cursos ativos e regulares de graduação em Educação Física de 87 IES do Brasil, sendo 106 licenciaturas (61\%) e 66 de bacharelados (39\%). Destes, foram identificados 37 currículos (20 licenciaturas e 17 bacharelados), distribuídos em 25 IES, que apresentaram pelo menos uma oferta de disciplina voltada para a área de PICS.

Quando avaliadas as diferenças regionais em comparação com a média nacional, observa-se a prevalência das disciplinas em cursos do Nordeste e Sudeste em termos absolutos. No entanto, quando realizada uma razão entre os cursos com PICS e o total, as regiões em que mais se concentram essas disciplinas é o Nordeste e o Sul, superando a média nacional, como se pode observar na Tabela 1.

\begin{tabular}{|c|c|c|c|}
\hline Região & $\begin{array}{l}\text { Currículos } \\
\text { analisados }\end{array}$ & $\begin{array}{c}\text { Curriculos } \\
\text { com PICS }\end{array}$ & Razão (\%) \\
\hline Norte & 19 & 0 & 0 \\
\hline Nordeste & 46 & 14 & 30,4 \\
\hline Centro-Oeste & 21 & 4 & 19,1 \\
\hline Sudeste & 56 & II & 19,6 \\
\hline Sul & 30 & 8 & 26,7 \\
\hline Brasil & 172 & 37 & 21,5 \\
\hline
\end{tabular}

A ausência de disciplinas envolvendo PICS em cursos de Educação Física da região Norte merece destaque por ser essa uma região com grande presença de comunidades indígenas, e, portanto, onde poderia haver maior espaço para discussões acerca de medicinas tradicionais em currículos da área de saúde.

Em muitos currículos brasileiros, a presença de discussões sobre as tradições indígenas e africanas estão presentes tendo como foco a perspectiva cultural ou, nas licenciaturas, escolar. Porém, o olhar sobre as práticas de cuidado e medicinas tradicionais, sobre as cosmovisões desses povos ou mesmo sobre uma antropologia da saúde não foi identificada em nenhum componente curricular, e nas disciplinas de PICS avaliadas tampouco.

Isso nos evidencia uma tendência existente na própria PNPIC que exclui as medicinas tradicionais ameríndias e africana do texto da política em detrimento de práticas pertencentes a um universo "branco" ou "amarelo branqueado", de tradição escrita e apropriadas pelas profissões da saúde, em especial a profissão médica (Moebus; Merhy, 2017), e também uma tendência da formação em Educação Física brasileira, em conservar suas raízes eurocêntricas e estadunidenses (Oliveira, 2018; Fonseca et al., 2012). 


\section{As disciplinas ofertadas}

Foram identificados 34 currículos (19,7\%) que possuíam disciplinas de PICS, racionalidade médicas ou medicinas tradicionais. Dentre os cursos analisados, $26(76,5 \%)$ foram provenientes de IES federais e $8(23,5 \%)$ de estaduais, sendo ao todo 19 licenciaturas $(55,8 \%)$ e 15 bacharelados $(44,2 \%)$. Foram analisadas as ementas e programas de 52 disciplinas, sendo 41 optativas e 10 obrigatórias.

O Grupo Temático de Racionalidades Médicas e PICS da Associação Brasileira de Saúde Coletiva (ABRASCO) publicou em Nota Técnica na Plenária Final do II Congresso Nacional de Práticas Integrativas e Complementares em Saúde, realizado em Sergipe em 2019, recomendações para uma formação de qualidade em PICS, sendo elas: carga horária prática supervisionada por profissional experiente; o ensino a distância como uma possibilidade informativa, mas não formativa; o trato com o conteúdo teórico conceitual adequado e paradigma que orienta determinada prática; uma formação orientada para atuação no SUS, com ênfase na Atenção Primária à Saúde e a valorização da atuação multiprofissional (Abrasco, 2019).

Tendo por base o documento da ABRASCO, foram criados os critérios de análise: se a disciplina contempla carga horária $(\mathrm{CH})$ teórico-prática ou apenas teórica; se propõe diálogo com o SUS; compatibilidade do programa proposto com a $\mathrm{CH}$; se tem proposta formativa apenas técnica ou na formação de uma visão integrativa de saúde (abordagem paradigmática) e se propõe o desenvolvimento de habilidades para atuação profissional ou se apenas vivencial. Os achados estão resumidos no Quadro 1.

Quadro I - Categorias de análise das disciplinas de PICS encontradas nos currículos de Educação Física, 2020

\begin{tabular}{|c|c|c|c|c|c|c|c|c|c|c|c|c|c|c|}
\hline \multirow[t]{2}{*}{ Categoria } & \multicolumn{2}{|c|}{ Currículo } & \multicolumn{2}{|c|}{$\begin{array}{c}\text { Carga horária } \\
\text { teórico- } \\
\text { prática }\end{array}$} & \multicolumn{2}{|c|}{$\begin{array}{l}\text { Diálogo } \\
\text { com o SUS }\end{array}$} & \multicolumn{2}{|c|}{$\begin{array}{c}\text { Compatibilidade } \\
\text { de } \mathrm{CH}\end{array}$} & \multicolumn{3}{|c|}{$\begin{array}{c}\text { Aspecto técnico } \times \text { Visão } \\
\text { Integrativa }\end{array}$} & \multicolumn{3}{|c|}{$\begin{array}{l}\text { Desenvolvimento } \\
\text { de habilidades ou } \\
\text { apenas vivencial }\end{array}$} \\
\hline & $\mathrm{OBG}$ & OPT & TP & $\mathrm{T}$ & Sim & Não & Sim & Não & Técnico & Integr. & Escolar & v & $\mathrm{H}$ & Teórico \\
\hline $\begin{array}{l}\text { PICS: meditação(2), } \\
\text { Massoterapia (3), } \\
\text { Yoga (8), Dança } \\
\text { circular (1), Práticas } \\
\text { corporais orientais (3), } \\
\text { Tai Chi Chuan (3), } \\
\text { Biodança (3), } \\
\text { terapias corporais (3) } \\
\text { e equoterapia (2) }\end{array}$ & 1 & 27 & 26 & 2 & 1 & 27 & 24 & 4 & 18 & 9 & 1 & 13 & 13 & 2 \\
\hline PICS RM & 0 & 5 & 4 & 1 & 2 & 3 & 5 & 0 & 1 & 4 & 0 & 2 & 2 & I \\
\hline Saúde e Espiritualidade & 0 & 3 & 0 & 3 & I & 2 & 3 & 0 & 0 & 3 & 0 & 1 & 0 & 2 \\
\hline PCA & 9 & 7 & 14 & 2 & 3 & 13 & 14 & 2 & 5 & 9 & 2 & 5 & II & 0 \\
\hline TOTAL & 10 & 42 & 44 & 8 & 7 & 45 & 46 & 6 & 24 & 25 & 3 & 21 & 26 & 5 \\
\hline
\end{tabular}

Inicialmente destaca-se que $88,4 \%$ das disciplinas de PICS avaliadas abordam diretamente práticas corporais na ementa e programa, como temática central ou como conteúdo a ser abordado. A temática não esteve presente em apenas 6 disciplinas, evidenciando ser essa a maior interface entre a área de Educação Física e PICS.
Foi identificada uma oferta curricular de PICS nos cursos de Educação Física composto por disciplinas majoritariamente optativas (8o\%), com carga horária teórico-prática $(84,6 \%)$ compatível com o programa proposto $(88,4 \%)$ e que não apresentam interface com o SUS $(86,5 \%)$. 
Além do predomínio da oferta optativa, 19 disciplinas (55,8\%) apresentaram carga horária acima de 60 horas. As demais, 15 disciplinas (44,2\%), variam entre 30 e 48 horas, das quais seis apresentaram um programa incompatível com o tempo de formação proposto.

Esses achados corroboram com o verificado pela literatura que aponta a predominância de disciplinas opcionais no ensino em PICS nas graduações de saúde no Brasil e no mundo. Com isso, aprofundam-se as lacunas formativas, e tanto sua capacidade de atuar com PICS de forma segura, sua inserção nos serviços de saúde e a comunicação e colaboração com profissionais que atuam com diferentes paradigmas em saúde tornam-se reduzidas (Nascimento et al., 2018).

A ausência de inserção e diálogo com o SUS pelas disciplinas de PICS se caracteriza como um grande problema identificado, que contraria as orientações do Conselho Nacional de Saúde para as Diretrizes Curriculares Nacionais (DCN) das graduações na área da saúde. Esse documento orienta uma formação voltada para atuação e defesa do SUS e o ensino em serviço desde o início da formação, além da construção de PPP e componentes curriculares que

considerem os pressupostos e fundamentos da promoção da saúde e seus determinantes, da Educação Popular em Saúde, e das Práticas Integrativas e Complementares como elementos constituintes da formação, objetivando que os egressos estejam preparados para reorientar os serviços de saúde; o fortalecimento da autonomia dos sujeitos e da cidadania, com olhar emancipatório; e a humanização e a integralidade na atenção à saúde. (Brasil, 2018a, p. 88)

Necessário ainda se faz mencionar que das 172 matrizes curriculares avaliadas, 154 apresentam pelo menos uma disciplina que contempla na ementa uma temática da saúde coletiva, porém apenas 33 possuem carga horária obrigatória satisfatória e fazem interface com o SUS com inserção prática ou comunitária. Isso revela que $11 \%$ dos cursos analisados não abordam nenhum conteúdo da grande área da saúde coletiva na sua grade curricular, e dos que abordam, aproximadamente $78 \%$ não respeitam as orientações das DCN.
Esses achados evidenciam o quão longe está a formação superior pública do que é proposto pela DCN dos cursos de graduação em Educação Física, uma vez que esta prevê a saúde como um dos três eixos articuladores, juntamente com esporte e cultura e lazer, orientando uma formação que contemple

políticas e programas de saúde; atenção básica, secundária e terciária em saúde, saúde coletiva, Sistema Único de Saúde, dimensões e implicações biológica, psicológica, sociológica, cultural e pedagógica da saúde; integração ensino, serviço e comunidade; gestão em saúde; objetivos, conteúdos, métodos e avaliação de projetos e programas de Educação Física na saúde. (Brasil, 2018b, p. 48)

Essa falta de alinhamento com os princípios do SUS e com a PNPIC evidencia o quão os profissionais vêm sendo pouco preparados para atuação na saúde pública e, como consequência, a oferta de PICS nos serviços tende a tornar-se distanciada das necessidades da população, descolada do seu papel social e excessivamente técnica e elitizada dentro do sistema público (Azevedo; Pelicioni, 2012).

Avaliou-se ainda que tanto existem disciplinas formativas, que se preocupam com o desenvolvimento de habilidades e capacitação para atuação profissional com PICS (50\%), como disciplinas informativas, que são aquelas com perfil mais vivencial $(40,4 \%)$ ou teórico $(9,6 \%)$ e que se voltam para o contato, reconhecimento e experimentação dessas práticas.

As disciplinas informativas são apontadas por Nascimento et al. (2018) como suficientes para o aconselhamento de usuários sobre o uso, porém, não para a aplicação de PICS e, apesar dos autores apontarem a prevalência dessas disciplinas nos currículos de saúde, o mesmo não foi observado para nos cursos de Educação Física analisados aqui.

As disciplinas foram categorizadas também de acordo com o eixo temático, sendo eles: (1) Modalidades de PICS; (2) PICS e racionalidades em saúde; (3) Saúde e Espiritualidade e (4) Práticas Corporais Alternativas.

As disciplinas voltadas a uma das 29 PICS foram maioria $(53,8 \%)$ e se destacam por priorizarem a aquisição de conhecimentos técnicos na prática 
enfocada sem fazer o debate paradigmático ou favorecer uma visão integrativa da saúde. Apesar de apresentarem como temas recorrentes o autoconhecimento, elementos das tradições e filosofias que fundamentam a prática-tema, energia vital, pontos e centros energéticos, saúde e espiritualidade e o sagrado, apenas uma minoria contemplou também uma visão integrativa de corpo (corpo-mente-espiritualidade) ou do ser humano (homem integrado com outros elementos do universo).

A visão integral aqui é compreendida segundo o descrito por Tesser e Luz (2008), que a definem como a capacidade do curador em interpretar o universo trazido pelo usuário, contemplando as muitas dimensões da vida e do adoecimento e relacionando a realidade que se apresenta com o saber especializado que orienta sua prática. Para os autores, esse processo interpretativo terapêutico é mediado pelas concepções e características das racionalidades que estruturam essas práticas, portanto, a integralidade estaria intimamente conectada às questões epistemológicas no que se refere à estrutura e configuração do saber especializado do curador e à relação do curador com esse saber.

Não produzir discussões epistemológicas nas disciplinas formativas em práticas que se orientam por outros paradigmas seria, portanto, favorecer uma apropriação meramente técnica desses saberes e, uma vez que a interpretação terapêutica precisa estar ancorada em uma racionalidade, essas práticas passam a funcionar de acordo à racionalidade biomédica que é predominante nos currículos e amplamente favorecida nos processos formativos em saúde.

Nascimento et al. (2018) vão trazer que diferente das racionalidades em saúde, as práticas terapêuticas embora possam compor alguma dimensão de uma racionalidade médica específica, podem ser aplicadas de forma isolada, e exemplifica com o que acontece na acupuntura praticada tanto em acordo com o paradigma vitalista e à racionalidade médica tradicional chinesa; como na acupuntura neurofuncional, que se aproxima da concepção biomédica. Os riscos, no entanto, desse tipo de formação é que o paradigma hegemônico seja privilegiado e, nesse caso, a proposta de ampliação para um olhar integrativo da saúde e do Ser, com complementariedade e coexistência entre saberes de raiz epistêmica diferentes seja perdida.

Nas categorias PICS e Racionalidades em Saúde e Saúde e Espiritualidade esse debate epistemológico, entre o paradigma biomédico e o energético-vitalista, esteve mais presente nas disciplinas. Todas tiveram ainda como característica uma abordagem mais generalista, sem se deter a apenas uma PICS, porém, enquanto as disciplinas da primeira categoria contemplam os temas da integralidade corpo-sujeitosociedade-ambiente, a emergência de terapias naturais e os sistemas terapêuticos complexos; as da segunda abordam a dimensão espiritual e a integração desta no cuidado em saúde, a formação holística do ser e o embate paradigmático entre racionalidade científica e espiritualidade.

Apesar do debate paradigmático, ambas as categorias apresentam componentes apenas optativos e majoritariamente teórico-vivenciais que não objetivam o desenvolvimento de habilidades ou a interface com o SUS, ou seja, disciplinas informativas. Dada a natureza não obrigatória e isolada nos currículos desses componentes, o debate paradigmático pode se tornar pontual e simplista, sendo um elemento que pouco contribui ou mesmo que atrapalha o entendimento das PICS, por não conseguir discutir satisfatoriamente a questão da importância da complementariedade em saúde (Nascimento et al., 2018).

As disciplinas categorizadas como PCA reuniram aquelas que se alinham com as propostas da educação somática, tendo como temas comuns a abordagem sistêmica do corpo, diversificação e consciência do movimento, sentido da corporeidade, experimentações corporais e autoconhecimento através de práticas corporais tradicionais milenares (ioga, meditação, shantala, shiatsu, tai-chi-chuan, respiração e o Qi Gong) ou contemporâneas holísticas e integrativas (pilates, ginástica natural e holística, educação somática atividades acrobáticas e circenses, calatonia, eutonia, antiginástica, massagens e danças circulares).

Se assemelham ainda por possuírem uma proposta pedagógica e formativa de educação integral do ser humano voltado para uma atuação profissional holística tanto na saúde como na educação. Dessa maneira, uma maioria das disciplinas objetiva 
o desenvolvimento de habilidades pedagógicas, havendo duas disciplinas voltadas exclusivamente para uma abordagem escolar das PCA e de cuidado em saúde.

Das dez disciplinas obrigatórias identificadas nesse estudo, nove puderam ser agrupadas nessa categoria, e isso pode estar relacionado com o fato das discussões sobre PCA e sua inserção curricular na Educação Física se darem há bastante tempo, desde a década de 1990 (Coldebella; Lorenzetto; Coldebella, 2004).

As PCA têm sua origem na década de 1960, inspiradas por movimentos socioculturais críticos desse período, e se aproximaram da Educação Física brasileira no momento de reabertura política de 1985, quando começaram a ser pensadas formas alternativas de compreender o corpo e experimentar o movimento. Essa aproximação se deu de maneira pontual, porém, possibilitou, na década seguinte, a incorporação das PCA como componente curricular em algumas universidades. Então temas como meditação, antiginástica, bioenergética e a educação somática foram introduzidos como possibilidades exploratórias para a Educação Física, ganhando ainda mais força com a incorporação de algumas dessas linguagens na PNPIC (Gomes; Almeida; Galak, 2019).

\section{Programas de pós-graduação $e$ grupos de pesquisa em PICS}

Foram avaliadas nas 87 IES incluídas nesse estudo a presença de abordagem sobre racionalidades médicas, medicinas tradicionais e PICS nas linhas de pesquisa dos PPG e Grupos de Pesquisa (GP) dessas instituições.

Apenas 19 IES (21,6\%) apresentaram linhas de pesquisa em PPG, das quais apenas duas tinham também graduações em Educação Física com disciplinas de PICS nos currículos. Além disso, não foi identificada correlação temática, estando as linhas de pesquisa relacionadas com áreas de fitoterapia e antropologia social (cosmologia ameríndia) e as disciplinas da graduação com PCA. A ausência de docentes da Educação Física nesses PPG também confirma esse distanciamento entre ensino e pesquisa.
O levantamento de dados na base corrente do Diretório dos Grupos de Pesquisa no Brasil do CNPq apresentou 765 resultados para os seguintes termos: Práticas Integrativas e Complementares, racionalidades em saúde, terapias integrativas, medicina tradicional, medicina alternativa, práticas corporais integrativas, práticas corporais alternativas, espiritualidade, plantas medicinais, fitoterapia, acupuntura, homeopatia, bioenergética, meditação, musicoterapia, arteterapia, biodança, aromaterapia, medicina antroposófica, ayurveda, dança circular, cromoterapia, constelação familiar, naturopatia, osteopatia, ozonioterapia, massoterapia, reflexoterapia, reiki, terapia comunitária integrativa, florais de Bach e yoga. outros termos buscados sem resultados foram: apiterapia, geoterapia, hipnoterapia, imposição de mãos, quiropraxia, shantala, medicina tradicional indígena, termalismo social e crenoterapia.

Após o cruzamento dos dados levantados com os dados disponibilizados pelo Observa PICS (Sousa; Silva; Ferreira, 2020), foram identificados 813 GP ativos no Brasil, até 12 de junho de 2020, que possuíam pelo menos uma linha de pesquisa em PICS, conforme verifica-se na Tabela 2.

\begin{tabular}{|c|c|c|c|}
\hline & $\begin{array}{l}\text { Total de } \\
\text { Grupos de } \\
\text { Pesquisa } \\
(2020)\end{array}$ & $\begin{array}{l}\text { GP com } \\
\text { linhas de } \\
\text { pesquisa } \\
\text { em PICS }\end{array}$ & Razão \\
\hline Norte & 3.145 & 97 & 3,08 \\
\hline Nordeste & 9.294 & 255 & 2,74 \\
\hline Centro-Oeste & 3.246 & 64 & 1,97 \\
\hline Sudeste & 13.617 & 229 & 1,68 \\
\hline Sul & 8.924 & 168 & 1,88 \\
\hline Brasil & 38.226 & 813 & 2,13 \\
\hline
\end{tabular}

A respeito da distribuição dos GP por região, observase que as regiões Nordeste e Sudeste apresentam maiores valores absolutos, corroborando com os achados de Sousa, Silva e Ferreira (2020), porém, avaliando esses valores em relação a quantidade 
total de GP existentes em cada região, é possível ter uma noção de como as PICS estão se inserindo no cenário de pesquisa do país. Nesse caso, observa-se que as regiões Norte e Nordeste apresentam valores acima da média nacional, indicando que as PICS nessas regiões possuem mais espaço na pesquisa quando comparadas às outras.

Não foram localizados nesse levantamento PPG especificamente em PICS, mas sim linhas de pesquisa em programas de áreas afins, dos quais 17 foram stricto sensu nas áreas de ciências da saúde/saúde coletiva (6); ciências farmacêuticas (6); ciências sociais (4) e bioética (1) e 12 programas lato sensu nas áreas de acupuntura (4); fitoterapia (3); arteterapia (2); florais (1); terapia ayurveda (1) e PICS (1).

Foi possível observar predominância da Fitoterapia e Plantas Medicinais como área de maior interesse tanto para os GP como também nos PPG (Figura 1).

\section{Gráfico I - Áreas contempladas pelas linhas de pesquisa em Práticas Integrativas e Complementares dos Programas de Pós-Graduação (1) e dos Grupos de Pesquisa (2) avaliados}

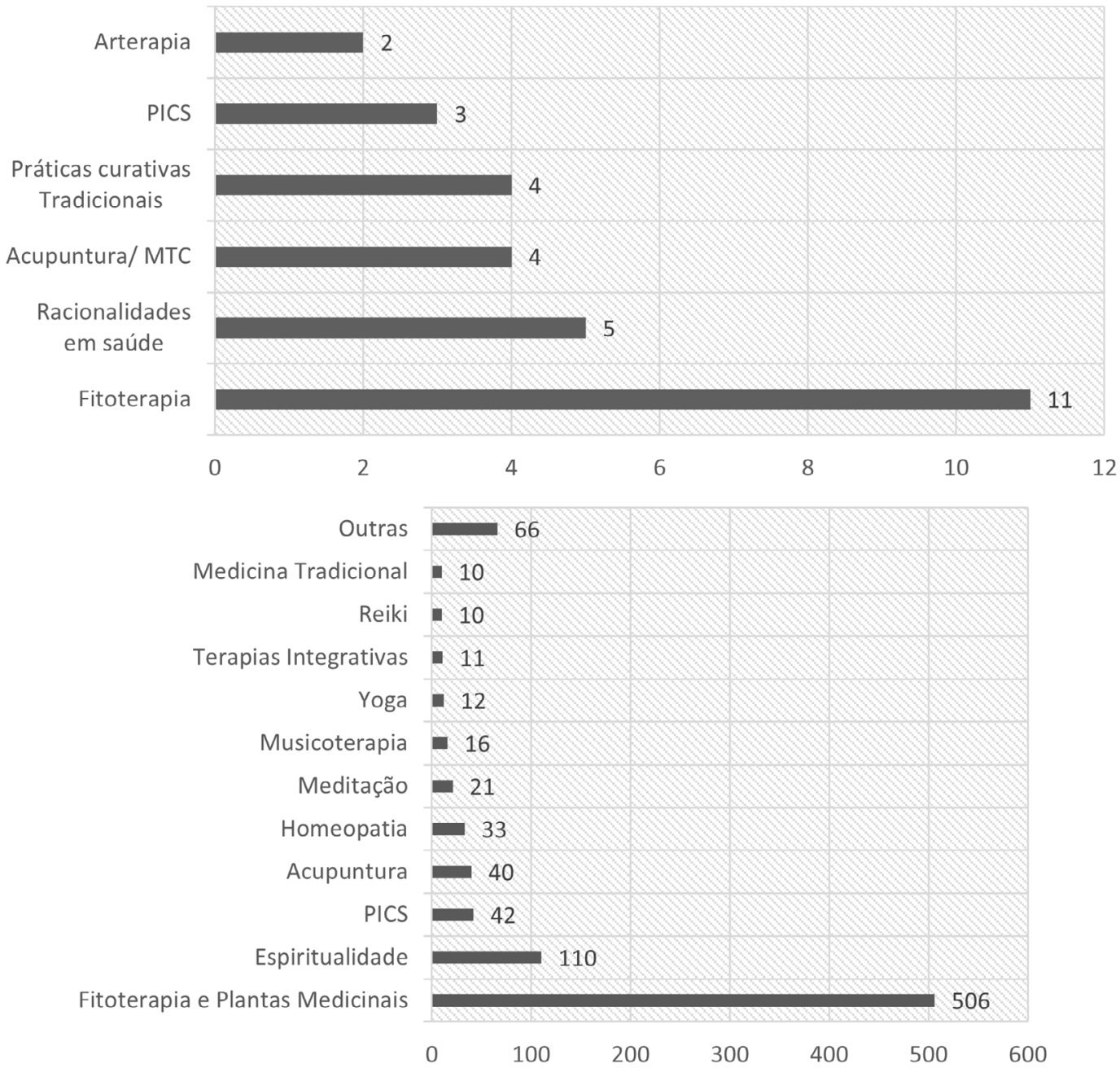

*A categoria "Outras" incluiu PICS com representatividade menor que I\%, sendo elas: ozonioterapia (9); arteterapia (8); medicina alternativa (6); aromaterapia, massoterapia, terapia comunitária integrativa (5); ayurveda e medicina antroposófica (4); bioenergética, constelação familiar, dança circular, osteopatia, práticas corporais alternativas e racionalidades em saúde (2); práticas corporais integrativas, práticas corporais orientais, termalismo, cromoterapia, biodança, naturopatia, florais de Bach, reflexoterapia (I).

${ }^{* *}$ Alguns Grupos de Pesquisa investigam mais de uma PICS. 
A predominância da fitoterapia corrobora com o mapeamento feito por Sousa, Silva e Ferreira (2020) que identificou predomínio de GP em plantas medicinais e fitoterápicos e pesquisas básicas e aplicadas em princípios ativos e fitoterapia. Também Moral-Munoz et al. (2014), apontaram que as publicações sobre o uso e propriedades de plantas medicinais apresentam melhor fator de impacto, maiores valores em número de citações e índice H na área da medicina tradicional integrativa e complementar.

Observa-se uma predisposição então da investigação científica se concentrar em práticas que já foram melhor apropriadas pelas profissões da saúde e cuja investigação científica pode ser melhor aplicada conforme as teorias e a nosografia biomédicas utilizando métodos que satisfazem ou se aproximam de padrões instituídos pela biomedicina (Sousa et al., 2012; Moebus; Merhy, 2017).

Da mesma forma, a pesquisa em Educação Física, segundo Manoel e Carvalho (2011) apresenta uma hegemonia da biodinâmica nos PPG, com $67,4 \%$ dos projetos de pesquisa a despeito de outras áreas, correspondendo uma tendência mundial ao fortalecimento das tecnociências nas universidades para a produção de inovação e pondo a ciência a serviço da economia e do mercado e não dos interesses sociais. Como consequência, a área de humanidades não apenas perde espaço na pesquisa, como também recursos, financiamento, desvalorização da sua produção, além da descredibilidade frente a uma ciência que "não considera a diversidade e a singularidade da natureza dos objetos de investigação" (p. 402).

Nessa perspectiva, foi identificado que dos GP que investigam PICS, apenas 16 (2\%) apresentam liderança de profissionais de educação física e em nenhum PPG em Educação Física foram identificadas linhas de pesquisa que abordem essa temática. Isso pode evidenciar que essa tendência de direcionar a pós-graduação para a área da biodinâmica está também afetando a pesquisa em PICS, uma área voltada para a produção de tecnologias leves e saberes contra hegemônicos.

Essa realidade de pesquisa se encontra totalmente desvinculada também da realidade dos serviços em que as diferentes práticas corporais (práticas corporais da medicina tradicional chinesa, yoga, biodança, dança circular, outras PCA) se caracterizam como a oferta de PICS predominante no SUS (Sousa et al., 2012; Barbosa et al., 2020). Uma vez que os achados nesse trabalho indicam as práticas corporais como principal área de interesse em PICS da Educação Física e a baixa participação dessa área na pesquisa com PICS, pode-se apontar esse descompasso como um dos fatores que contribuem para essa desconexão entre a realidade dos serviços públicos e a investigação científica.

\section{Conclusão}

Quando avaliada a formação dos profissionais de Educação Física em PICS no ensino superior público brasileiro, é perceptível a fragilidade da temática nos currículos pela pouca inserção do tema, baixa participação e protagonismo da área nas linhas de pesquisa em PICS de PPC e em lideranças de Grupos de Pesquisa.

A formação em PICS nos cursos avaliados se caracteriza pela disciplinarização (disciplinas isoladas nos currículos), componentes predominantemente optativos de baixo impacto na formação, sem interface com outros profissões da saúde e sem o debate paradigmático que ancore e justifique essas disciplinas em currículos já bastante biomédicos em que prevalece o modelo ocidental de corpo, saúde e cuidado. 0 risco desse tipo de formação fragmentada é a perda de sentido das PICS pela captura do modelo biomédico que continua se reproduzindo dentro de uma lógica "mais holística", porém, incapaz de integrar de fato elementos diversos no olhar sobre a saúde.

A interlocução com os princípios e diretrizes do SUS é também muito incipiente em grande parte das disciplinas de PICS, e isso evidencia um entrave para a inserção dessas práticas nos serviços de maneira a contribuir com a consolidação do sistema e da própria PNPIC.

Destaca-se a inexistência de componentes que contemplem as medicinas tradicionais brasileiras (indígenas e africanas), estando as disciplinas em PICS voltadas para as práticas corporais ocidentais ou pertencentes a racionalidades orientais. Em certa medida, ao pautar de maneira incipiente nos currículos esse debate das epistemologias dos 
povos tradicionais brasileiros e por não abordar suas medicinas nas discussões de saúde da área, o ensino superior público em Educação Física, assim como em outras áreas da saúde, se torna reprodutor de um apagamento já existente na PNPIC e conivente com a exclusão histórica desses povos dos espaços formais e suas consequências decorrentes disso.

A Educação Física encontra-se ainda bastante afastada do campo da pesquisa em PICS, não possuindo protagonismo nos GP e não sendo identificadas linhas de pesquisa nessa temática em nenhum PPG em Educação Física do Brasil. Esse distanciamento do debate acadêmico sobre PICS gera várias lacunas, não apenas formativas, mas na produção científica sobre essas práticas.

A ausência de diretórios para cadastro das atividades extensionistas das universidades brasileiras, talvez um importante indicativo da desvalorização dessa haste do tripé do ensino superior, impossibilita que se mapeie de forma ampla, como realizada nesse trabalho, os projetos de extensão voltados às PICS desenvolvidos nessas instituições. Estudos futuros sobre a participação da Educação Física nas atividades extensionistas com PICS se fazem necessários, tendo em vista que esse também se configura como um espaço de formação importante não avaliado aqui.

Futuras investigações que enfoquem o interesse dos estudantes pelas disciplinas de PICS; os indicadores de matrículas, aprovação e evasão nessas disciplinas e o campo de atuação do profissional de Educação Física com PICS são fundamentais para qualificar o debate acerca da temática e elucidar de que forma essas lacunas formativas têm impactado a área.

Diante da perspectiva traçada nesse trabalho, destacamos a necessidade da qualificação da formação em PICS nas graduações em Educação Física em IES públicas brasileiras, ampliação da inserção nas especializações e pós-graduação comprometidos com o SUS, maior participação na pesquisa na área e ampliação do debate sobre a formação e investigações sobre os currículos.

\section{Referências}

ABRASCO - ASSOCIAÇÃO BRASILEIRA DE SAÚDE COLETIVA. Nota técnica sobre formação em RM-PICS. Lagarto: 2019.
AZEVEDO, E.; PELICIONI, M. C. F. Práticas integrativas e complementares de desafios para a educação. Trabalho, Educação e Saúde, Rio de Janeiro, v. 9 n. 3, p. 361-378, 2012. DOI: 10.1590/S1981-77462011000300002

BARBOSA, F. E. S. et al. Oferta de Práticas Integrativas e Complementares em Saúde na Estratégia Saúde da Família no Brasil. Cadernos de Saúde Pública, Rio de Janeiro, v. 36, n. 1, eoo208818, 2020. DOI: 10.1590/0102$311 \times 00208818$

\section{BRASIL. Política Nacional de Práticas}

Integrativas e Complementares no SUS: atitude de ampliação de acesso. 2. ed. Brasília, DF: Ministério da Saúde, 2006.

BRASIL. Conselho Nacional de Saúde. Resolução $\mathrm{n}^{0} 569$, de 8 de dezembro de 2017. Diário Oficial da União, Brasília, DF, 26 fev. de 2018a.

BRASIL. Ministério da Educação. Resolução nº 6, de 18 de dezembro de 2018. Institui Diretrizes Curriculares Nacionais dos Cursos de Graduação em Educação Física e dá outras providências. Diário Oficial da União, Brasília, DF, 19 dez. 2018b. BRASIL. Lista de Instituições de Ensino Superior Ativas Cadastro e-MEC. Brasília, DF: Ministério da Educação, 2020.

COLDEBELLA, A. O. C.; LORENZETTO, L. A.; COLDEBELLA, A. Práticas Corporais alternativas: formação em Educação Física. Motriz, Rio Claro, v. 10, n. 2, p. 111-122, 2004.

CORREA, N.; SOARES, M. C. F.; MUCCILLO-BAISCH, A. L. Conhecimento do tema plantas medicinais e fitoterápicos como instrumento tecnológico na formação dos acadêmicos de enfermagem. Vittalle, Rio Grande, v. 30, n. 2, p. 38-46, 2018. DOI: 10.14295/ vittalle.v3oi2.7496

COUTO, A. G. et al. Conhecimento, uso e aceitação de acadêmicos de medicina sobre as práticas integrativas e complementares. Vittalle, Rio Grande, v. 30, n. 1, p. 56-62, 2018. DOI: 10.14295/vittalle.v3oi1.7448

FONSECA, S. A. et al. Notas preliminares ABENEFS sobre a Associação Brasileira de Ensino da Educação Física para a Saúde (ABENEFS). Caderno FNEPAS, Rio de Janeiro, v. 2, p. 38-48, 2012. 
FRAGA, A. B.; CARVALHO, Y. M.; GOMES, I. M. Políticas de formação em Educação Física e Saúde Coletiva. Trabalho, Educação e Saúde, Rio de Janeiro, v. 10, n. 3, p. 367-386, 2012. DOI: 10.159o/ S1981-77462012000300002

GOMES, L.; ALMEIDA, F. Q.; GALAK, E. As práticas corporais alternativas e a Educação Física: uma revisão sistemática. Motrivivência, Florianópolis, v. 31, n. 57, p. 1-20, 2019. DOI: 10.5007/21758o42.2019e 54167

GONTIJO, M. B. A.; NUNES, M. F. Práticas integrativas e complementares: conhecimento e credibilidade de profissionais do serviço público de saúde. Trabalho, Educação e Saúde, Rio de Janeiro, v. 15, n. 1, p. 301-320, 2017. DOI: 10.1590/1981-7746-solooo40

MANOEL, E. J.; CARVALHO, Y. M. Pós-graduação na educação física brasileira: a atração (fatal) para a biodinâmica. Educação e Pesquisa, São Paulo, v. 37, n. 2, p. 389-406, 2011. DOI: 10.1590/S1517-97022011000200012

MOEBUS, R. L. N; MERHY, E. E. Genealogia da Política Nacional de Práticas Integrativas e Complementares. Saúde em Redes, Porto Alegre v. 3, n. 2, p. 145-152, 2017. DOI: $10.18310 / 2446-4813 \cdot 2017 \mathrm{~V} 3 n 2 p 145-15^{2}$

MORAL-MUNOZ, J. A. et al. Analyzing the research in Integrative \& Complementary Medicine by means of science mapping. Complementary Therapies in Medicine, Amsterdam, v. 22, n. 2, p. 409-418, 2014. DOI: 10.1016/j.ctim.2014.02.003

NASCIMENTO, M. C. et al. Formação em Práticas Integrativas e Complementares em Saúde: desafios para as universidades públicas. Trabalho, Educação e Saúde, Rio de Janeiro, v. 16, n. 2, p. 751-772, 2018. DOI: 10.1590/1981-7746-soloo13o

NOGUEIRA, M. I.; NASCIMENTO, M. C. Homeopatia e Acupuntura na formação médica da Universidade Federal Fluminense: trajetórias e perspectivas. Diversitates International Journal, Niterói, v. 10, n. 3, p. 64-79, 2018.

OLIVEIRA, R. C. Educação Física, saúde e formação profissional. Physis, Rio de Janeiro, v. 28, n. 3, e280302, 2018. DOI: 10.159o/so103-73312018280302
SALLES, L. F.; HOMO, R. F. B.; SILVA, M. J. P. Situação do ensino das práticas integrativas e complementares nos cursos de graduação em enfermagem, fisioterapia e medicina. Cogitare Enfermagem, Curitiba, v. 19, n. 4, p. 741-746, 2014. DOI: $10.5380 /$ ce.v19i4.35140

SANTOS, G. M. et al. O ensino da fitoterapia nos cursos de nutrição em um estado do Nordeste brasileiro. Revista Brasileira de Obesidade, Nutrição e Emagrecimento, São Paulo, v. 13, n. 77, p. 68-72, 2019.

SOUSA, I. M. C. et al. Práticas integrativas e complementares: oferta e produção de atendimentos no SUS e em municípios selecionados. Cadernos de Saúde Pública, Rio de Janeiro, v. 28, n. 11, p. 2143-2154, 2012. DOI: 10.1590/So102-311X2012001100014

SOUSA, I. M. C.; SILVA, G. K. F.; FERREIRA, C. T. Ciência aberta em PICS: grupos de pesquisa no Brasil e práticas integrativas e complementares em saúde - relatório de pesquisa. Recife: Fiocruz, 2020.

TEIXEIRA, M. Z. Homeopatia: desinformação e preconceito no ensino médico. Revista Brasileira de Educação Médica, Rio de Janeiro, v. 31, n. 1, p. 15-20, 2007. DOI: 10.1590/So10o55022007000100003

TESSER, C. D.; LUZ, M. T. Racionalidades médicas e integralidade. Ciência \& Saúde Coletiva, Rio de Janeiro, v. 13, n. 1, p. 195-206, 2008. DOI: 10.159o/ S1413-81232008000100024

\section{Contribuição dos autores}

Barboni contribuiu na concepção, delineamento, análise e interpretação de dados, redação, revisão e aprovação final do artigo. Carvalho contribuiu no delineamento, revisão e aprovação final do artigo.

Recebido: 21/01/2021

Reapresentado: 16/03/2021

Aprovado: 29/03/2021 